\title{
Age-Related Changes in Sensitivity of Tomato (Solanum lycopersicum L.) Leaves to Continuous Light
}

\author{
T. G. Shibaeva ${ }^{a}$ *, A. V. Mamaev ${ }^{a}$, E. G. Sherudilo ${ }^{a}$, E. N. Ikkonen ${ }^{a}$, and A. F. Titov ${ }^{a}$ \\ ${ }^{a}$ Institute of Biology, Karelian Research Center, Russian Academy of Sciences, Petrozavodsk, 185910 Russia \\ *e-mail: shibaeva@krc.karelia.ru
}

Received October 28, 2020; revised November 8, 2020; accepted November 16, 2020

\begin{abstract}
Tomato (Solanum lycopersicum L.) belongs to the crops that are the most sensitive to continuous lighting (CL). We studied age-dependent changes in the sensitivity of tomato leaves to CL. The leaves exposed to $C L$ from a lag-phase of their growth exhibited pronounced chlorosis with the loss of $30 \%$ chlorophyll after 2 weeks. The values of the maximum $\left(F_{\mathrm{v}} / F_{\mathrm{m}}\right)$ and actual $\left(\varphi_{\mathrm{II}}\right)$ quantum yields of the PSII photochemical activity were decreased, the photosynthesis rate was suppressed, and the relative electrolyte leakage was enhanced. In contrast, the leaves were less sensitive to CL if they had passed their early growth (lag-phase) under normal light conditions (16-h photoperiod) and encountered the CL as late as in the log-phase. In this case, the chlorophyll content, the photosynthesis rate, and the electrolyte leakage were close to the levels of the control leaves grown at the 16-h photoperiod except for the antioxidant enzymes-catalase, ascorbate peroxidase, and guaiacol peroxidase-which were more active. The conclusion was drawn that the age-related changes in the CL-sensitivity are due to the difference in activities of the antioxidant enzymes. In general, the elder plants were less sensitive to CL than the younger ones.
\end{abstract}

Keywords: Solanum lycopersicum, photoperiod, continuous lighting, chlorosis, leaf growth, pigments, antioxidant enzymes

DOI: $10.1134 /$ S1021443721040154

\section{INTRODUCTION}

In recent years the interest grows to the use of continuous lighting (CL) for crop growing in greenhouses and especially in closed systems of plant factories with artificial lighting (PFAL), which are being widely exploited in some countries (United States, Japan, China, Korea, etc.) [1]. If other growing conditions are optimal, the plant biomass is determined to a large extent by an amount of the absorbed light energy, which depends on light intensity and duration. Therefore, CL can augment plant biomass and yield but only providing that this factor is not harmful $[2,3]$. In fact, long photoperiods cause interveinal chlorosis or necrosis in many plant species. In particular, the symptoms of the photodamage arise on CL-treated tomato, eggplant, sweet pepper, cucumber, and some other crops [2-4]. Not only plant species but also cultivars, e.g., these of leaf lettuce, differ significantly in their sensitivity to CL. Nevertheless, using long (including 24-h) photoperiods with relatively low photon flux density is economically profitable because of a reduction in initial and operational energy costs $[5,6]$. Real-

Abbreviations: AOS—antioxidant system; APO—ascorbate peroxidase; CAT catalase; CL-continuous lighting; GPO-guaiacol peroxidase; LMA-leaf mass per area; REL_-relative electrolyte leakage; TBA-thiobarbituric acid; WUE-water-use efficiency. location of the light energy consumption from daytime to night periods, when the load is the least, diminishes the energy costs because its night tariff is lower than the day one (by up to 50\%) in many countries [7]. In addition, light sources help supplying the plants with a necessary warmth in the night [8]. The use of dynamic temperature control strategy enables cultivation of such CL-sensitive crops as cucumber, tomato, and sweet pepper under CL in greenhouses with supplemental lighting [7,9-11]. The search for more efficient growing technologies is now ongoing [12].

Although CL is being applied practically, the mechanisms of plant sensitivity and adaptation to this factor remain obscure. The current hypotheses, explaining how plants response to CL and suggesting different mechanisms of CL-tolerance, have not been experimentally proven so far. For example, they consider such phenomena as starch hyperaccumulation, constant photooxidative exertion, signaling action towards photoreceptors, and inconsistence between the frequencies of internal circadian biorhythms and the external light/dark cycle (circadian asynchrony) $[3,13-15]$. It is also assumed that the leaf photodamage by 24-h light is a consequence of an unbalanced excitation in PSI and PSII [16].

It is worth noting that the age of the whole plants and the inspected leaves were not taken into account 
in the publications of different authors on the plant responses to CL. Indeed, CL can be switched on at different phases of leaf growth and plant ontogenesis. However, the influence of CL on plant ontogenesis was not investigated in depth, although this factor was intensively employed in genetic and breeding studies as a tool accelerating the development of some plant species [17]. As to the age-related changes in the sensitivity of entire plants and their leaves to CL, these phenomena have not been actually studied and discussed since the corresponding mention in the paper of W.S. Hillman [18]. The lack of comprehension of the leaf and plant ontogenetic peculiarities of responses to CL hinders revelation of the processes determining the plant tolerance and adaptation to CL. This gap in knowledge also gives birth to the contradictory interpretations of the successful or unsuccessful plant cultivation under long-term $C L$ and the mechanisms underlying the plant responses to CL.

Here, we studied tomato plants, which are generally CL-sensitive. The purposes were to reveal how the sensitivity of the leaves to CL depends on (1) the leaf growth phase, (2) the leaf number on the main stem, and (3) the age of the plant at the moment of the CL switching on.

\section{MATERIALS AND METHODS}

Tomato plants (Solanum lycopersicum L., Verlioka plus F1 hybrid) were studied. The seeds were germinated for 2 days in Petri dishes on a filter paper moistened with distilled water in the darkness at $28^{\circ} \mathrm{C}$. The seeds starting germination were transplanted to $7 \times 7-\mathrm{cm}$ plastic containers with sand. The seedlings were grown in a Vötsch growth chamber (Germany) at an air temperature of $23^{\circ} \mathrm{C}$, a 16 -h photoperiod, a PAR of $250 \mu \mathrm{mol} /\left(\mathrm{m}^{2} \mathrm{~s}\right)$, and $70 \%$ air RH. They were supplied with a complete nutrient solution containing $(\mathrm{mg} / \mathrm{L})$ $226 \mathrm{~N}, 55 \mathrm{P}, 370 \mathrm{~K}, 180 \mathrm{Ca}, 40 \mathrm{Mg}, 45 \mathrm{~S}, 17 \mathrm{Na}, 52 \mathrm{Cl}$, $2.5 \mathrm{Fe}, 0.6 \mathrm{Mn}, 0.35 \mathrm{~B} ; 0.3 \mathrm{Zn}, 0.15 \mathrm{Cu}$, and $0.05 \mathrm{Mo}$ at $\mathrm{pH} 6.2-6.4$.

The plants at the ages of 14,18 , or 30 days after sowing (DAS) were transferred to the continuously lighted (24-h photoperiod) chambers (Fig. 1b), while the control plants still grew at a $16-\mathrm{h}$ photoperiod.

To determine the phases of leaf growth, which the plants are passing at a moment of the light changeover, the leaf growth dynamics was analyzed at a 16-h photoperiod (Fig. 1a). If the CL regimen was switched on the 14th DAS (Fig. 1b: A), plant leaves of the first and second numbers were passing the growth log-phase (and were longer than $3 \mathrm{~cm}$ ) and the leaves of the third and higher numbers were at the lag-phase (shorter than $1 \mathrm{~cm}$ at the lag- 1 and shorter than $2.5-3 \mathrm{~cm}$ at the lag-2) (Fig. 1). On the 18th DAS, fifth leaves passed the lag-phase (shorter than $3 \mathrm{~cm}$ ) (Fig. 1b: B). On the 30th DAS, the first 7-8 leaves were at the log-phase (longer than $3 \mathrm{~cm}$ ) (Fig. 1b: C). In all cases, the leaves
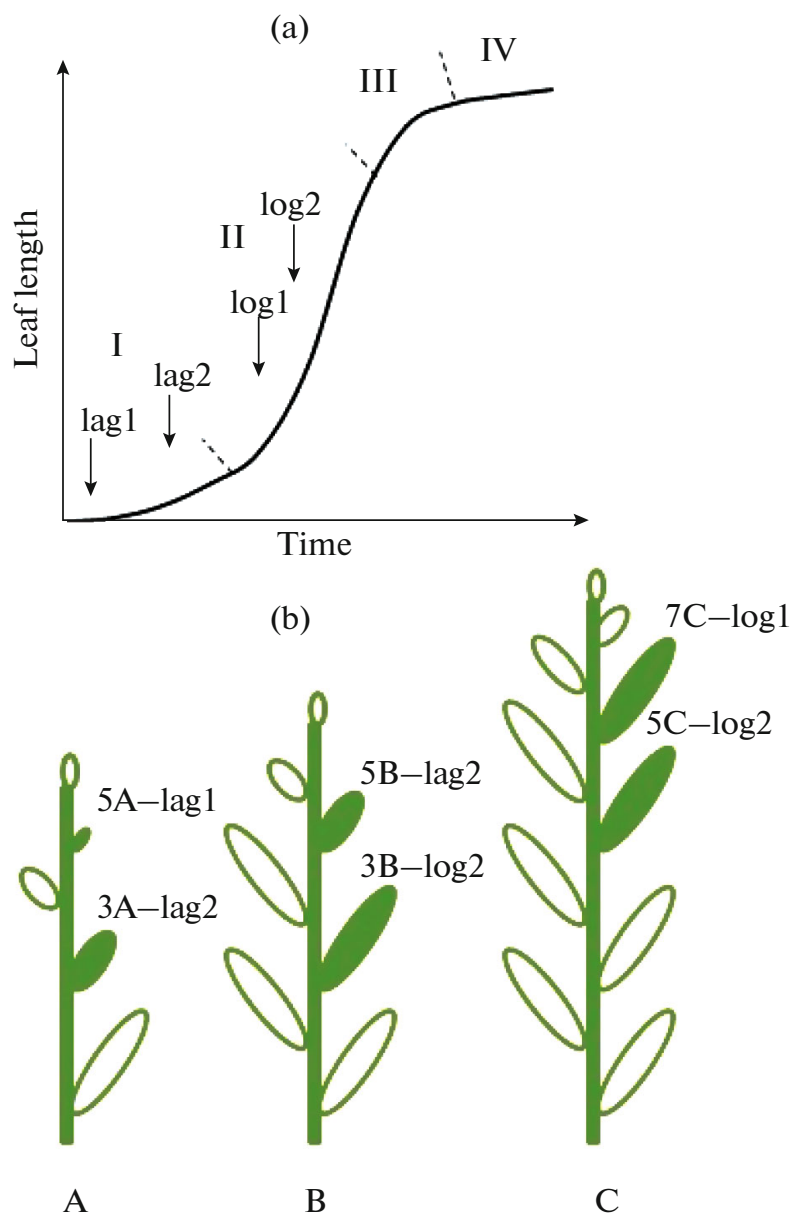

Fig. 1. (a) Schematic growth curve of Solanum lycopersicum leaf. The phases of leaf growth: I-lag-phase; II-phase of logarithmic growth (log-phase); III-phase of growth retardation; IV-stationary phase. The arrows indicate the moments of switching on continuous lighting (CL). (b) The experimental design. The plants were subjected to CL at the age of (A) 14, (B) 18, or (C) 30 days after sowing. The third, fifth, and seventh leaves (filled pictures), which had passed different growth phases upon the oneset of CL, were analyzed. They were designated as: 3A-lag2-the third leaf in the middle of the lag-phase; 5A-lag1-the fifth leaf at the start of lag-phase; 3B- $\log 2$-the third leaf in the middle of the log-phase; 5B-lag2-the fifth leaf in the middle of the lag-phase; $5 \mathrm{C}-\log 2$ the fifth leaf in the middle of the $\log$-phase; $7 \mathrm{C}-\log 1$ - the seventh leaf at the start of log-phase.

of the same sequential number were used as controls in comparison with the CL-treated ones to avoid agerelated differences between the counterparts.

The value of leaf mass per area (LMA) was calculated as a ratio of a dry mass of the lamina discs to their area. Eight discs were cut from each leaf with an 8 - $\mathrm{mm}$ in diameter cork borer. The dry weight of the discs was determined after their drying to a constant weight at $105^{\circ} \mathrm{C}$.

The total content of chlorophylls $a$ and $b$ was determined in $96 \%$ ethanol extracts with a SF-2000 spec- 
trophotometer (Spektr, Russia) and was calculated by the conventional formulas [19]. The dynamics of the related chlorophyll content was express-monitored with a SPAD 502 Plus chlorophyll meter (Konica Minolta, Japan) in the course of an experiment. We previously demonstrated the applicability of this equipment for rapid nondestructive assay of chlorophyll in the leaves with interveinal chlorosis [20].

The chlorophyll fluorescence was measured with a MINI-PAM fluorimeter (Walz, Germany) under pulse-modulated illumination. The maximum quantum yield of PSII photochemical activity $\left(F_{\mathrm{v}} / F_{\mathrm{m}}\right)$ was measured after 20-min leaf adaptation to darkness. The actual quantum yield $\left(\varphi_{\text {II }}\right)$ of the PSII photochemical activity was determined in all the plants (after 30 -min light adaptation for control plants) according to the formula [21]: $\left.\varphi_{\mathrm{II}}=\Delta F / F_{\mathrm{m}}^{\prime}=\left(F_{\mathrm{m}}^{\prime}-F\right) / F_{\mathrm{m}}^{\prime}\right)$.

The net photosynthesis $\left(A_{n}\right)$ and leaf transpiration (Tr) were evaluated with a portable HCM-1000 photosynthetic system (Walz, Germany) at a leaf temperature of $23^{\circ} \mathrm{C}$ and PAR of 300 or $1000 \mu \mathrm{mol} /\left(\mathrm{m}^{2} \mathrm{~s}\right)$. The gas-exchange parameters were measured not earlier than $2 \mathrm{~h}$ after the start of a light period in the control treatment. The water-use efficiency (WUE) was calculated as a $A_{n}: \operatorname{Tr}$ ratio.

The membrane permeability was estimated through a relative electrolyte leakage (REL) from the leaf tissues. Ten 4-mm in diameter leaf discs, were rinsed with distilled water to remove the cellular sap from the cut surface, were blotted with filter paper and placed into $10 \mathrm{~mL}$ of distilled water. After 2-h shaking of test-tubes with the discs at $23^{\circ} \mathrm{C}$, the electric conductivity of the solution (E1) was measured by an Ekspert-002 conductometer furnished with an UEP-P-S sensor for microsamples (Ekoniks-Ekspert, Russia) at the same temperature. Thereafter, the test-tubes were heated until boiling, were cooled to room temperature, and the full electrolyte leakage (E2) was evaluated by the conductivity of the solution after the membrane damage by boiling. The relative electrolyte leakage was calculated as a percentage of the full leakage by the formula $\mathrm{REL}=100 \times \mathrm{E} 1 / \mathrm{E} 2 \%$.

The extent of lipid peroxidation (LPO) was estimated by malondialdehyde (MDA) content, which was assayed by measuring the absorption at the maximum of $532 \mathrm{~nm}$ by colored trimetine complex formed upon reactions of thiobarbituric acid (TBA) with the lipid peroxidation products. The leaves $(0.1 \mathrm{~g})$ were ground in $2 \mathrm{~mL}$ of $20 \%$ trichloroacetic acid (TCA) followed by centrifugation of the homogenate at $15000 \mathrm{~g}$ for $10 \mathrm{~min}$. The supernatant $(1 \mathrm{~mL})$ was mixed with $1 \mathrm{~mL}$ $20 \%$ TCA containing $0.5 \%$ thiobarbituric acid (TBA). The mixture was heated at $95^{\circ} \mathrm{C}$ for $30 \mathrm{~min}$ followed by centrifugation at $10000 \mathrm{~g}$ for $5 \mathrm{~min}$. The optical density at $532 \mathrm{~nm}$ and the nonspecific absorption at $600 \mathrm{~nm}$ were measured. The MDA content was calculated using the molar extinction coefficient $155 \mathrm{mM}^{-1} \mathrm{~cm}^{-1}$ and was expressed as $\mu \mathrm{mol} / \mathrm{g}$ dry wt of the leaves.

The activities of the antioxidant enzymes-catalase (CAT, EC 1.11.1.6), ascorbate peroxidase (APO, EC 1.11.1.11), and guaiacol peroxidase (GPO, EC 1.11.1.7)-were also analyzed. The leaves were homogenized in $50 \mathrm{mM}$ phosphate buffer, $\mathrm{pH} 7.8$, the homogenate was centrifuged at $15000 \mathrm{~g}$ for $10 \mathrm{~min}$ at $4^{\circ} \mathrm{C}$, and the activities were analyzed in the supernatant. CAT was assayed spectrophotometrically by the decomposition of exogenous hydrogen peroxide (decrease in optical density at $240 \mathrm{~nm}$ ). The APO activity was determined by the decrease of the absorbance at $290 \mathrm{~nm}$ in the presence of $0.5 \mathrm{mM}$ ascorbic acid and $0.5 \mathrm{mM} \mathrm{H}_{2} \mathrm{O}_{2}$. The GPO activity was measured by the $\mathrm{H}_{2} \mathrm{O}_{2}$-dependent oxidation of guaiacol (rise in the absorbance at $470 \mathrm{~nm}$ ) in the mixture of $2.5 \mathrm{~mL} 50 \mathrm{mM}$ potassium phosphate buffer $(\mathrm{pH} 6.1)$, $1 \mathrm{~mL} 1 \%$ hydrogen peroxide, $1 \mathrm{~mL} 1 \%$ guaiacol, and $10 \mu \mathrm{L}$ of an enzymatic preparation. The activities of the enzymes were normalized to $1 \mathrm{~g}$ of dry mass of the leaves; their specific activities were normalized to $1 \mathrm{mg}$ of protein. The total protein content was assayed by Bradford with BSA as a standard.

The state of the leaves (occurrence of chlorosis or necrosis) was visually estimated (Fig. 2a), and nondestructive measurements (chlorophyll content in SPAD units, $F_{\mathrm{v}} / F_{\mathrm{m}}$, and $\varphi_{\mathrm{II}}$ ) were performed every $3-4$ days. Other measurements were done after 3 weeks of the CL treatment.

Every experiment was repeated twice. The figures represent means $(n \geq 6)$ and their SEs. The differences between the means were determined with the analysis of variance using the Statistica program package, version 8.0.550.0 (StatSoft, Inc.). The differences between means were taken as significant at $P<0.05$.

\section{RESULTS \\ Effect of the Leaf Growth Phase}

In the plants initially grown under the 16 -h photoperiod, the content of chlorophyll and the maximum $\left(F_{\mathrm{v}} / F_{\mathrm{m}}\right)$ and actual $\left(\varphi_{\mathrm{II}}\right)$ quantum yields of the PSII photochemical activity decreased in comparison with the control plants one week after switching to the 24-h photoperiod (Figs. 3, 4). However, not all the leaves displayed such changes. Thus, the plants exposed to CL from the 14th DAS (Fig. 1b: A) manifested these traits (and the subsequent chlorosis (Fig. 2a)) (Figs. 2b: A; 3) on the 3rd and younger leaves, which were at the lag-phase at the onset of CL. In the plants subjected to the CL from the 18th DAS, the damage was found in the 5th and younger leaves (Figs. 2b: B; 3), which were at the lag-phase at the beginning of $C L$ treatment.

To relate the CL-sensitivity of the leaf with its growth phase, the responses of the third or fifth leaves, which had been exposed to CL from either lag- or log- 
(a)

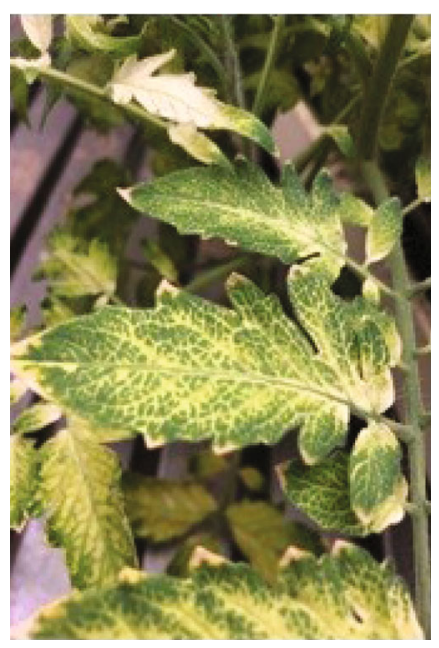

(b)

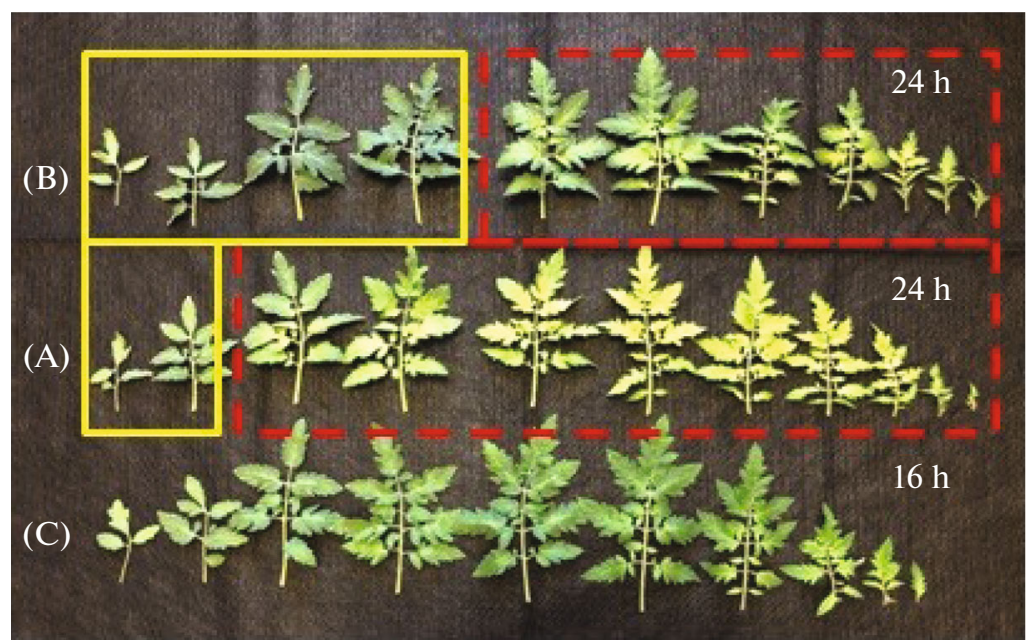

Fig. 2. (a) Interveinal chlorosis of $S$. lycopersicum leaves caused by continuous lighting. (b) The leaves of (C) the control plants grown under 16-h photoperiod. The leaves subjected to CL at the age of (A) 14 or (B) 18 days (see Fig. 1). The dotted frames comprise the leaves exposed to CL from the lag-phase and the solid-line frames represent those CL-treated from the log-phase.

phase, were examined. The leaves 3A-lag2 and 3B-log2 and $5 \mathrm{~B}-\operatorname{lag} 2$ and $5 \mathrm{C}-\log 2$, i.e., the leaves of equal ordinal numbers but passing the different growth phases at the beginning of CL, were compared. It was found that both third and fifth leaves, subjected to CL from the lag-phase (3A-lag2 and 5B-lag2), manifested the lesser chlorophyll content (Fig. 4c, Table 1) and the parameters of chlorophyll fluorescence $\left(F_{\mathrm{v}} / F_{\mathrm{m}}\right.$ and $\varphi_{\text {II }}$ ) (Figs. 4a, 4b) than the CL-treated leaves from the log-phase. The photosynthesis rates in the third and fifth leaves were 70 and $50 \%$ and 45 and $30 \%$ lower than the control at PAR of 300 and $1000 \mu \mathrm{mol} /\left(\mathrm{m}^{2} \mathrm{~s}\right)$, respectively (Table 1$)$. The WUE values were by 45 and $30 \%$ lower than the control in the third and fifth leaves, respectively. Meanwhile, these leaves exhibited considerably increased indexes of membrane permeability (REL) by 142 and $45 \%$ and LPO (MDA content) by 42 and $58 \%$, respectively, (Table 1 ). This witnesses for a strong oxidative stress. The CAT activity was found to be reduced by $54 \%$ in the 3A-lag2 leaf, and the GPO activity was enhanced by $54 \%$ in the leaf 5B-lag2 as compared with the control (Table 1).

The third and fifth leaves, which were CL-treated starting from the log-phase of their growth (3B-log2 and $5 \mathrm{C}-\log 2$ ), did not significantly differ from the control in the chlorophyll content and the dynamics of $F_{\mathrm{v}} / F_{\mathrm{m}}$ and $\varphi_{\mathrm{II}}$ (Fig. 4 , Table 1 ). The $A_{n} 300$ values were at the control level in the third and fifth leaf, and the $A_{n 1000}$ values were lower by $30 \%$ than the control in the third leaf (Table 1). The LMA indexes markedly exceeded the control-by $19 \%$ in the third and $107 \%$ in the fifth leaf. The third leaf demonstrated the enhancement of MDA content-by $20 \%$ above the control, while this parameter was comparable with the 

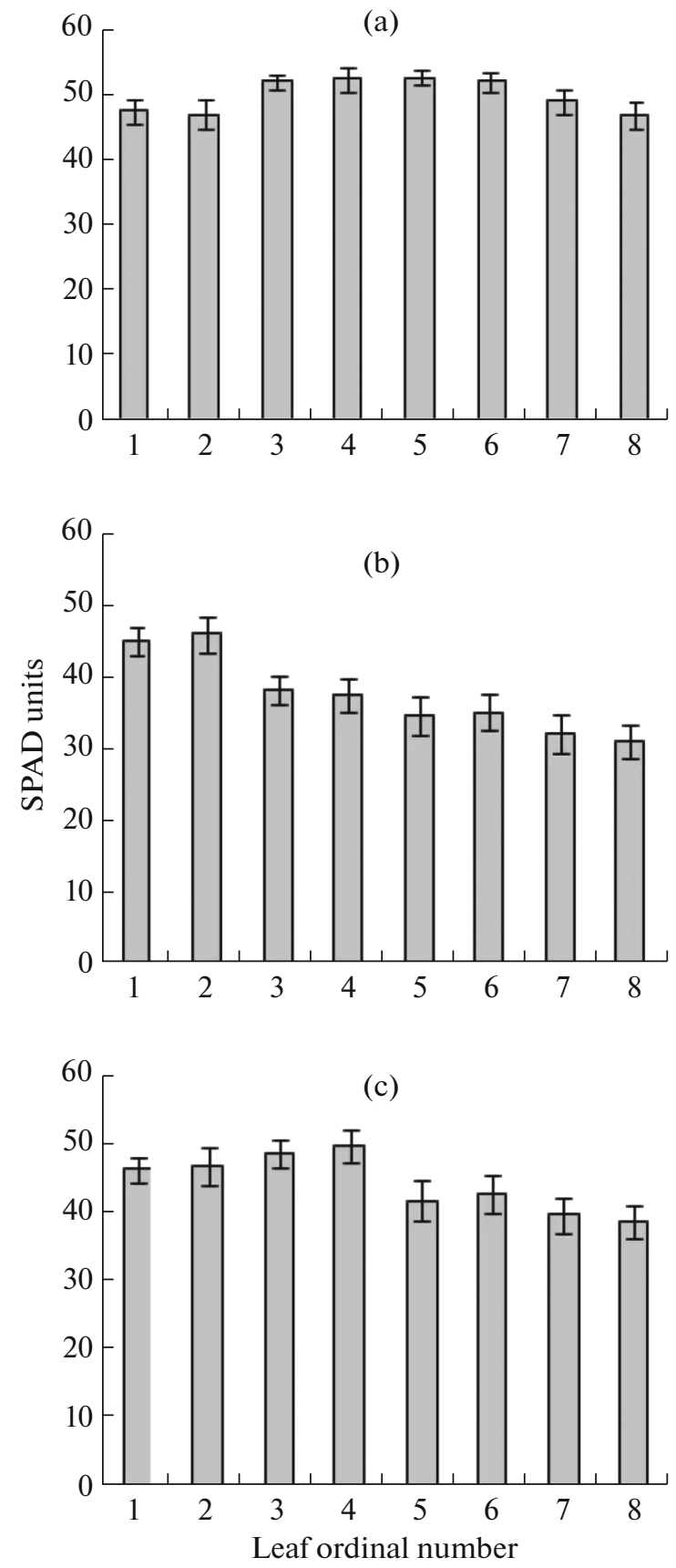

Fig. 3. Relative content of chlorophyll in the S. lycopersicum leaves of (a) the control plants grown under 16-h photoperiod, and the plants grown under CL from the age of (b) 14 , or (c) 18 days.

control in the fifth leaf. The antioxidant enzymes CAT, APO, and GPO were more active in both third and fifth leaves as compared with the control (Table 1).

\section{Effect of the Leaf Position on the Plant}

To test how the leaf sensitivity to CL depends on its position (defined by the ordinal number) on the plant,
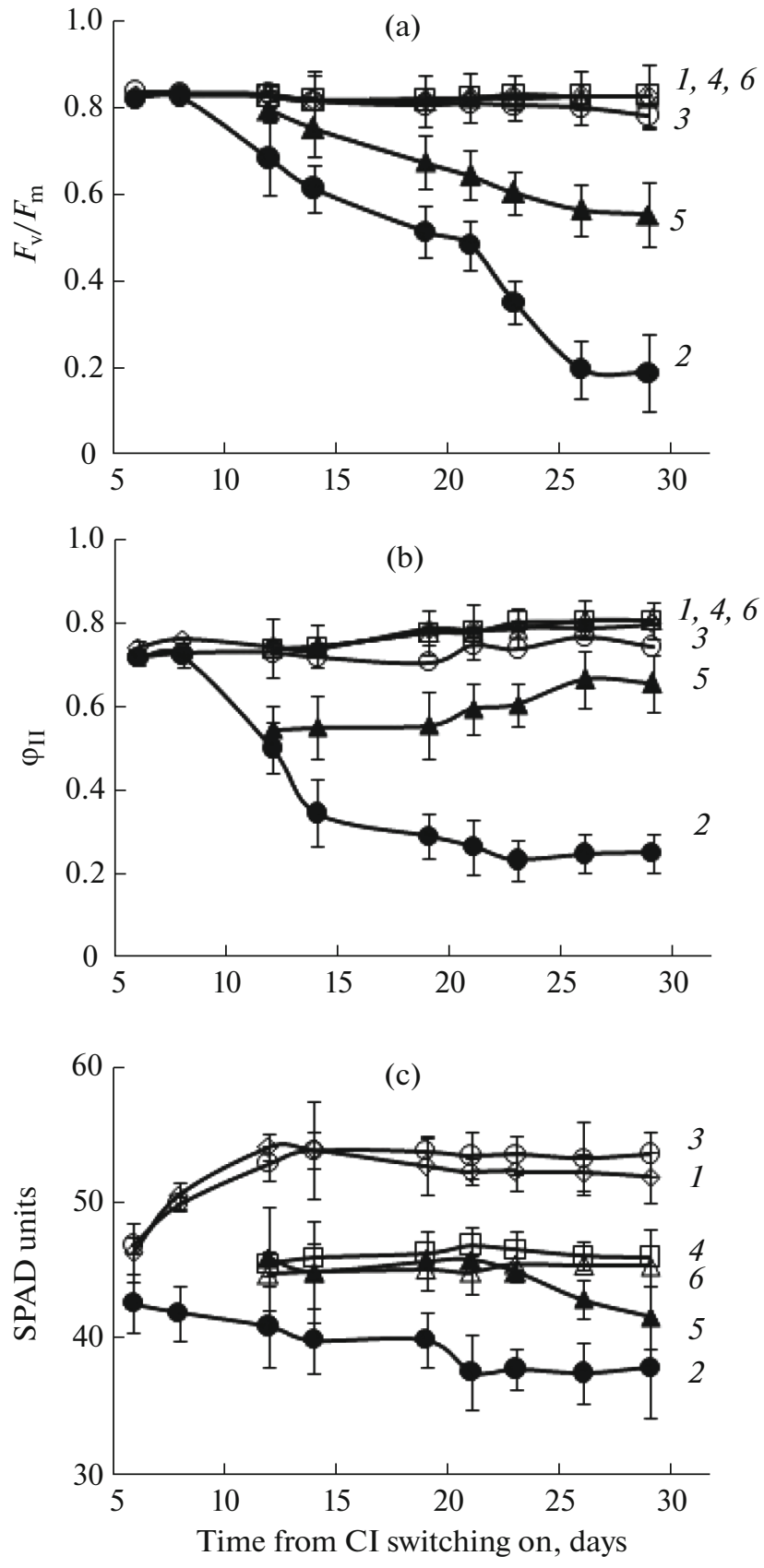

Fig. 4. (a) Maximum $F_{\mathrm{v}} / F_{\mathrm{m}}$ and (b) actual $\varphi_{\mathrm{II}}$ quantum yields of the PSII photochemical activity, and (c) relative content of chlorophyll in the $S$. lycopersicum leaves. (1) The third and (4) fifth leaves of the plants grown under 16-h photoperiod; (2) the 3A-lag2 and (5) 5B-lag2 leaves of the plants treated by CL from the lag-phase; (3) the leaf 3B-lag2 and $(6)$ leaf $5 \mathrm{C}-\log 2$ of the plants treated by $\mathrm{CL}$ from the log-phase.

the leaves of different numbers, which were at the same growth phase during the CL onset, were compared. These were 3A-lag2 vs. 5A-lag 1 and $5 \mathrm{C}-\log 2$ vs. 7C- $\log 1$ (Fig. 1b).

In the third and fifth leaves (3A-lag2 and 5A-lag1), which had been exposed to CL from the lag-phase, the 
Table 1. Physiological and biochemical parameters of the Solanum lycopersicum leaves exposed to continuous lighting for 3 weeks from the lag- or log-phase of growth (\% of the control)

\begin{tabular}{|c|c|c|c|c|}
\hline \multirow{2}{*}{ Parameter } & \multicolumn{2}{|c|}{ Third leaf } & \multicolumn{2}{|c|}{ Fifth leaf } \\
\hline & 3A-lag2 & $3 \mathrm{~B}-\log 2$ & 5B-lag2 & $5 C-\log 2$ \\
\hline $\begin{array}{l}\text { Chl }(a+b) \text { content } \\
\mathrm{mg} / \mathrm{g} \text { dry wt }\end{array}$ & $75^{*}$ & 96 & $79 *$ & 98 \\
\hline$A_{n 300}, \mu \mathrm{mol} \mathrm{CO} 2 /\left(\mathrm{m}^{2} \mathrm{~s}\right)$ & $30^{*}$ & 105 & $56^{*}$ & 103 \\
\hline$A_{n 1000}, \mu \mathrm{mol} \mathrm{CO} 2 /\left(\mathrm{m}^{2} \mathrm{~s}\right)$ & $51^{*}$ & $71 *$ & $68^{*}$ & 98 \\
\hline $\begin{array}{l}\text { WUE, } \mu \mathrm{mol} \\
\mathrm{CO}_{2} / \mathrm{mmol} \mathrm{H}_{2} \mathrm{O}\end{array}$ & $54^{*}$ & 102 & $68^{*}$ & 101 \\
\hline $\mathrm{LMA}, \mathrm{mg} / \mathrm{cm}^{2}$ & 92 & $119 *$ & 107 & $207^{*}$ \\
\hline REL, \% & $242^{*}$ & 90 & $145 *$ & 101 \\
\hline $\begin{array}{l}\text { MDA content, } \mu \mathrm{mol} / \mathrm{g} \\
\text { dry wt }\end{array}$ & $142^{*}$ & $120 *$ & $158 *$ & 108 \\
\hline $\begin{array}{l}\text { CAT activity, } \mu \text { mol } \\
\mathrm{H}_{2} \mathrm{O}_{2} /(\text { mg protein min })\end{array}$ & $46^{*}$ & $127^{*}$ & 109 & $130^{*}$ \\
\hline $\begin{array}{l}\text { APO activity, } \\
\mu \mathrm{mol} /(\mathrm{mg} \text { protein } \mathrm{min})\end{array}$ & 114 & $146^{*}$ & 107 & $121^{*}$ \\
\hline $\begin{array}{l}\text { GPO activity, } \\
\mu \mathrm{mol} /(\mathrm{mg} \text { protein } \mathrm{min})\end{array}$ & 87 & $151^{*}$ & $154^{*}$ & $486^{*}$ \\
\hline
\end{tabular}

The leaves of the corresponding ordinal numbers grown under the $16-\mathrm{h}$ photoperiod are taken as the controls. Significant differences from the control are designated *. In the control samples, all the parameters are defined as $100 \%$. Their absolute values are given below. The control third leaf: Chl $(a+b)$ content $12.8 \mathrm{mg} / \mathrm{g}$ dry wt; $A_{n} 3006.0 \mu \mathrm{mol} \mathrm{CO} 2 /\left(\mathrm{m}^{2} \mathrm{~s}\right) ; A_{n} 100010.7 \mu \mathrm{mol} \mathrm{CO} 2 /\left(\mathrm{m}^{2} \mathrm{~s}\right) ; \mathrm{WUE}$ $7.48 \mu \mathrm{mol} \mathrm{CO} 2 / \mathrm{mmol} \mathrm{H}_{2} \mathrm{O}$; LMA $2.6 \mathrm{mg} / \mathrm{cm}^{2}$; REL 22.4\%; MDA content $253 \mu \mathrm{mol} / \mathrm{g}$ dry wt; CAT activity $2.6 \mu \mathrm{mol} \mathrm{H}_{2} \mathrm{O}_{2} /(\mathrm{mg}$ protein $\mathrm{min})$; APO activity $35 \mu \mathrm{mol} /(\mathrm{mg}$ protein $\mathrm{min})$; GPO activity $47 \mu \mathrm{mol} /(\mathrm{mg}$ protein $\mathrm{min})$. The control fifth leaf: Chl $(a+b)$ content $11.7 \mathrm{mg} / \mathrm{g}$ dry wt; $A_{n} 3006.3 \mu \mathrm{mol} \mathrm{CO} 2 /\left(\mathrm{m}^{2} \mathrm{~s}\right) ; A_{n} 10008.2 \mu \mathrm{mol} \mathrm{CO} 2 /\left(\mathrm{m}^{2} \mathrm{~s}\right) ; \mathrm{WUE} 9.28 \mu \mathrm{mol} \mathrm{CO}_{2} / \mathrm{mmol} \mathrm{H}_{2} \mathrm{O} ; \mathrm{LMA} 1.4 \mathrm{mg} / \mathrm{cm}^{2} ; \mathrm{REL}$ 21.5\%; MDA content $153 \mu \mathrm{mol} / \mathrm{g}$ dry wt; CAT activity $4.6 \mu \mathrm{mol} \mathrm{H}_{2} \mathrm{O}_{2} /(\mathrm{mg}$ protein min); APO activity $43 \mu \mathrm{mol} /(\mathrm{mg}$ protein min); GPO activity $35 \mu \mathrm{mol} /(\mathrm{mg}$ protein $\mathrm{min})$.

chlorophyll content and the $F_{\mathrm{v}} / F_{\mathrm{m}}$ and $\varphi_{\mathrm{II}}$ values markedly decreased with time in comparison with the control (Fig. 5, Table 2). The $A_{n 300}, A_{n} 1000$, and WUE indexes decreased by $50-70 \%$ below the control in the third leaf and were only 4-7\% of the control levels in the fifth leaf (Table 2). The REL indexes exceeded the control ones by 142 and $67 \%$ in the 3A-lag2 and 5A-lag1, respectively. The MDA content was higher by $42 \%$ above the control in the third leaf. This leaf possessed the less active CAT (by 54\%), while the fifth leaf manifested the strongly diminished activities of the three enzymes: CAT by $48 \%$, APO by $60 \%$, and GPO by $66 \%$ (Table 2 ).

The fifth and seventh leaves, which were at the logphase of growth at the onset of CL, did not significantly differ from the control in their chlorophyll content, parameters of chlorophyll fluorescence, photosynthesis rate, and WUE, REL, and MDA levels (Fig. 5, Table 2). Here, the LMA values exceeded the control ones by 107 and $80 \%$ in the $5 \mathrm{C}-\log 2$ and $7 \mathrm{C}-\log 1$ leaves, respectively. In both the leaves, the activities of CAT and APO were higher by $20-30 \%$, and the activity of GPO was more than 2-3 times higher than the control (Table 2).
In the leaves treated by CL from the lag-phase, the degree of chlorosis increased with the leaf number (Figs. 2b, 3).

\section{Effect of Plant Age}

To reveal how the plant age determines the leaf responses to $\mathrm{CL}$, we compared the leaves that were at the same growth phases at the oneset of CL-treatment, but their parent plants were of different age. The leaves 3A-lag2 and 5B-lag2, as well as 3B-log2 and $5 \mathrm{C}-\log 2$, were inspected (Fig. 1b).

In the 3A-lag2 and 5B-lag2 leaves, most of the tested parameters were lower than in the control (Table 1, Fig. 4). The chlorophyll fluorescence (Fig. 4) and the photosynthesis rate (Table 1) in the 5B-lag2 leaves considerably exceeded those of 3A-lag2. Meanwhile, the 5B-lag2 leaves exhibited a markedly lower REL index and twofold higher activity of CAT and GPO than the 3A-lag2 leaves (Table 1).

Both 3B- $\log 2$ and 5C- $\log 2$ leaves coincided with the control in respect to the $F_{\mathrm{v}} / F_{\mathrm{m}}, \varphi_{\mathrm{II}}$, chlorophyll content, $A_{n} 300$, and WUE. However, the 3B-log2 
Table 2. Physiological and biochemical parameters of the $S$. lycopersicum leaves of different position on the main stem exposed to continuous lighting for 3 weeks (\% of the control)

\begin{tabular}{|c|c|c|c|c|}
\hline \multirow{2}{*}{ Parameter } & \multicolumn{2}{|c|}{ Lag-phase } & \multicolumn{2}{|c|}{ Log-phase } \\
\hline & 3A-lag2 & 5A-lag1 & $5 C-\log 2$ & $7 C-\log 1$ \\
\hline Chl $(a+b)$ content & $75^{*}$ & $78 *$ & 98 & 98 \\
\hline$A_{n 300}, \mu \mathrm{mol} \mathrm{CO} \mathrm{CO}_{2} /\left(\mathrm{m}^{2} \mathrm{~s}\right)$ & $30 *$ & $4 *$ & 103 & 99 \\
\hline$A_{n 1000}, \mu \mathrm{mol} \mathrm{CO} 2 /\left(\mathrm{m}^{2} \mathrm{~s}\right)$ & $51^{*}$ & $4^{*}$ & 98 & 96 \\
\hline $\begin{array}{l}\text { WUE, } \mu \mathrm{mol} \\
\mathrm{CO}_{2} / \mathrm{mmol} \mathrm{H}_{2} \mathrm{O}\end{array}$ & $54^{*}$ & $7 *$ & 101 & 97 \\
\hline $\mathrm{LMA}, \mathrm{mg} / \mathrm{cm}^{2}$ & 92 & 93 & $207^{*}$ & $180^{*}$ \\
\hline REL, \% & $242 *$ & $167 *$ & 101 & 105 \\
\hline $\begin{array}{l}\text { MDA content, } \mu \mathrm{mol} / \mathrm{g} \\
\text { dry wt }\end{array}$ & $142 *$ & 107 & 108 & 110 \\
\hline $\begin{array}{l}\text { CAT activity, } \mu \text { mol } \\
\mathrm{H}_{2} \mathrm{O}_{2} /(\text { mg protein } \mathrm{min})\end{array}$ & $46^{*}$ & $52 *$ & $130 *$ & $120 *$ \\
\hline $\begin{array}{l}\text { APO activity, } \\
\mu \mathrm{mol} /(\mathrm{mg} \text { protein } \mathrm{min})\end{array}$ & 114 & $40 *$ & $121^{*}$ & $125^{*}$ \\
\hline $\begin{array}{l}\text { GPO activity, } \\
\mu \mathrm{mol} /(\mathrm{mg} \text { protein } \mathrm{min})\end{array}$ & 87 & $34^{*}$ & $486^{*}$ & $377^{*}$ \\
\hline
\end{tabular}

The leaves of the corresponding ordinal numbers grown under $16-\mathrm{h}$ photoperiod were taken as the controls. Significant differences from the control are designated $*$. In the control samples, all the parameters are defined as $100 \%$. Their absolute values are given below. The control third leaf: Chl $(a+b)$ content $12.8 \mathrm{mg} / \mathrm{g}$ dry wt; $A_{n} 3006.0 \mu \mathrm{mol} \mathrm{CO} 2 /\left(\mathrm{m}^{2} \mathrm{~s}\right) ; A_{n} 100010.7 \mu \mathrm{mol} \mathrm{CO}_{2} /\left(\mathrm{m}^{2} \mathrm{~s}\right) ; \mathrm{WUE} 7.48 \mu \mathrm{mol}$ $\mathrm{CO}_{2} / \mathrm{mmol} \mathrm{H} \mathrm{H}_{2} \mathrm{O}$; LMA $2.6 \mathrm{mg} / \mathrm{cm}^{2}$; REL 22.4\%; MDA content $253 \mu \mathrm{mol} / \mathrm{g}$ dry wt; CAT activity $2.6 \mu \mathrm{mol} \mathrm{H}_{2} \mathrm{O}_{2} /\left(\mathrm{mg}_{\mathrm{protein}} \mathrm{min}\right)$; APO activity $35 \mu \mathrm{mol} /(\mathrm{mg}$ protein min); GPO activity $47 \mu \mathrm{mol} /(\mathrm{mg}$ protein min). The control fifth leaf: $\mathrm{Chl}(a+b) \mathrm{content} 11.7 \mathrm{mg} / \mathrm{g}$ dry wt; $A_{n} 3006.3 \mu \mathrm{mol} \mathrm{CO} 2 /\left(\mathrm{m}^{2} \mathrm{~s}\right) ; A_{n} 10008.2 \mu \mathrm{mol} \mathrm{CO} /\left(\mathrm{m}^{2} \mathrm{~s}\right) ; \mathrm{WUE} 9.28 \mu \mathrm{mol} \mathrm{CO} 2 / \mathrm{mmol} \mathrm{H}_{2} \mathrm{O} ; \mathrm{LMA} 1.4 \mathrm{mg} / \mathrm{cm}^{2} ; \mathrm{REL} 21.5 \%$; MDA content $153 \mu \mathrm{mol} / \mathrm{g}$ dry wt; CAT activity $4.6 \mu \mathrm{mol} \mathrm{H} \mathrm{O}_{2} /(\mathrm{mg}$ protein min); APO activity $43 \mu \mathrm{mol} /(\mathrm{mg}$ protein min); GPO activity $35 \mu \mathrm{mol} /\left(\mathrm{mg}\right.$ protein min). The control seventh leaf: Chl $(a+b)$ content $10.9 \mathrm{mg} / \mathrm{g}$ dry wt; $A_{n} 3006.2 \mu \mathrm{mol} \mathrm{CO}_{2} /\left(\mathrm{m}^{2} \mathrm{~s}\right) ; A_{n} 1000$ $8.3 \mu \mathrm{mol} \mathrm{CO} 2 /\left(\mathrm{m}^{2} \mathrm{~s}\right)$; WUE $9.18 \mu \mathrm{mol} \mathrm{CO} 2 / \mathrm{mmol} \mathrm{H}_{2} \mathrm{O}$; LMA $1.4 \mathrm{mg} / \mathrm{cm}^{2}$; REL $21.1 \%$; MDA content $148 \mu \mathrm{mol} / \mathrm{g}$ dry wt; CAT activity $4.2 \mu \mathrm{mol} \mathrm{H}_{2} \mathrm{O}_{2} /($ mg protein min); APO activity $39 \mu \mathrm{mol} /(\mathrm{mg}$ protein min); GPO activity $37 \mu \mathrm{mol} /(\mathrm{mg}$ protein min).

leaves displayed the $A_{n} 1000$ values $30 \%$ lower and the MDA index somewhat higher than the 5B-lag2 leaves (Table 1). The activity of GPO was three times higher in the $5 \mathrm{C}-\log 2$ than in the $3 \mathrm{~B}-\log 2$.

\section{DISCUSSION}

In some our experiments, the tomato leaves manifested different sensitivity to CL, which can be assessed through several physiological and biochemical parameters. The difference in visual symptoms between the leaves of one plant was observed earlier [18], but this phenomenon was not characterized in terms of physiology and biochemistry. It follows from our results that the growth phase, which the leaf passes through at a moment of the light changeover, determines the leaf responses to the CL. Thus, in leaves undergoing the lag-phase at the start of CL progressively decreased maximum and actual quantum yields of the PSII photochemical activity, the photosynthesis rate, and the chlorophyll content. Meanwhile, their LPO intensity (MDA accumulation) and the membrane permeability (REL) increased witnessing for oxidative stress. Afterwards, interveinal chlorosis developed in these leaves. On the contrary, the leaves that were at an elder stage (log-phase) of growth displayed the same photo- synthetic activity and chlorophyll content as the control with the exception of the photosynthesis rate of the third leaf, which decreased under light at saturating intensity. Here, the hallmarks of the plant oxidative stress did not appear. The enhanced plant tolerance to excessive light is usually associated with an activation of the antioxidant system [22]. In our case, in such leaves the activity of antioxidant enzymes were higher, which might prevent their photodamage. For example, the activities of CAT, APO, and GPO in the third leaf, which had been subjected to CL from the log-phase, were, respectively, by 80,32 , and $64 \%$ higher than in the leaf that had undergone CL treatment from the lag-phase of the growth. For the fifth leaf, these values were 21,14 , and $332 \%$, respectively.

The observed dependence of the CL -sensitivity of the leaf on its growth phase is rather expected. The literature on photoperiodism reports many examples of ontogenetic changes in the plant sensitivity to a photoperiodical stimulus of a flowering initiation [23]. It is also known that photoperiodism controls not only a passage to the generative development but also such processes as leaf growth, pattern of branching, growth of the root system, accumulation and distribution of dry matter, and tillering. In the meantime, according to our results, the responses of plants and their leaves 
to CL are contrast to those accompanying the changes in the sensitivity to the photoperiodical stimulus. For instance, the younger and elder leaves are different in their sensitivity to changes in the photoperiod, so that the actively growing leaves are the most sensitive. More complex relationships concerning the leaf age also exist. For example, the cocklebur (Xanthium pennsylvanicum) leaves, which are smaller than $2 \mathrm{~cm}^{2}$ in area, are yet insensitive to the photoperiodical induction of the flowering, while the leaves attaining a half of their ultimate size are maximally sensitive to this stimulus. In the course of the subsequent growth, the sensitivity diminishes again [24]. Here, as well as in our experiments with CL, the mature leaves lose their sensitivity partially or completely. However, in the case of photoperiodical stimulus, the youngest leaves undergo the preinductive stage and, hence, are incapable (do not possess a competence) of perception of the stimulating signals. To compare, CL alters the youngest leaves most of all, while the growing and mature leaves scarcely manifest visible damage or these symptoms arise much later. It is also known that the leaf sensitivity to the changes in the photoperiod is age-related: the elder the plant, the shorter the induction period is required to start flowering. By contrast, the elder plants are less sensitive to CL. Our present experiments and the earlier publication [18] on tomato demonstrate the highest sensitivity of the plants bearing 4-7 leaves, while the younger or elder plants are less sensitive. We only found that on the elder plants the photosynthetic activity was less reduced and the oxidative stress was less induced in the leaves treated by CL since the lag-phase. If the plants had grown under CL from the very beginning, all the leaves, from the first one, were obviously photodamaged according to chlorosis and the fall of the chlorophyll content below ten SPAD units (data not shown).

The revealed higher activities of the antioxidant enzymes-CAT, APO, and GPO-deserve special attention. The activation of catalase and superoxide dismutase was also found earlier by other authors in cultivated tomato plants under the conditions of constant temperature and lighting [25]. In eggplant, superoxide dismutase, CAT, and GPO are activated as early as the second day of CL treatment [26]. In lettuce plants, CL elevates the levels of nonenzymatic components of the antioxidant system (AOS), such as L-ascorbic acid and glutathione, and activates APO and glutathione reductase. These changes occur at the $F_{\mathrm{v}} / F_{\mathrm{m}}$ ratio above 0.8 , indicating the absence of photooxidative damage [1]. Of low-molecular antioxidants, ascorbic acid demonstrates the increase in concentration after 48-h CL [27]. This inspired the authors to apply the short-term (2-day) CL before the crop harvest to enrich the plants with ascorbate in order to produce so-called functional food with the enhanced antioxidant capacity. In addition, the rise in the antiradical (assayed with 2,2-diphenyl-1-picrylhydrazyl) and the superoxide dismutase activities and the accu-
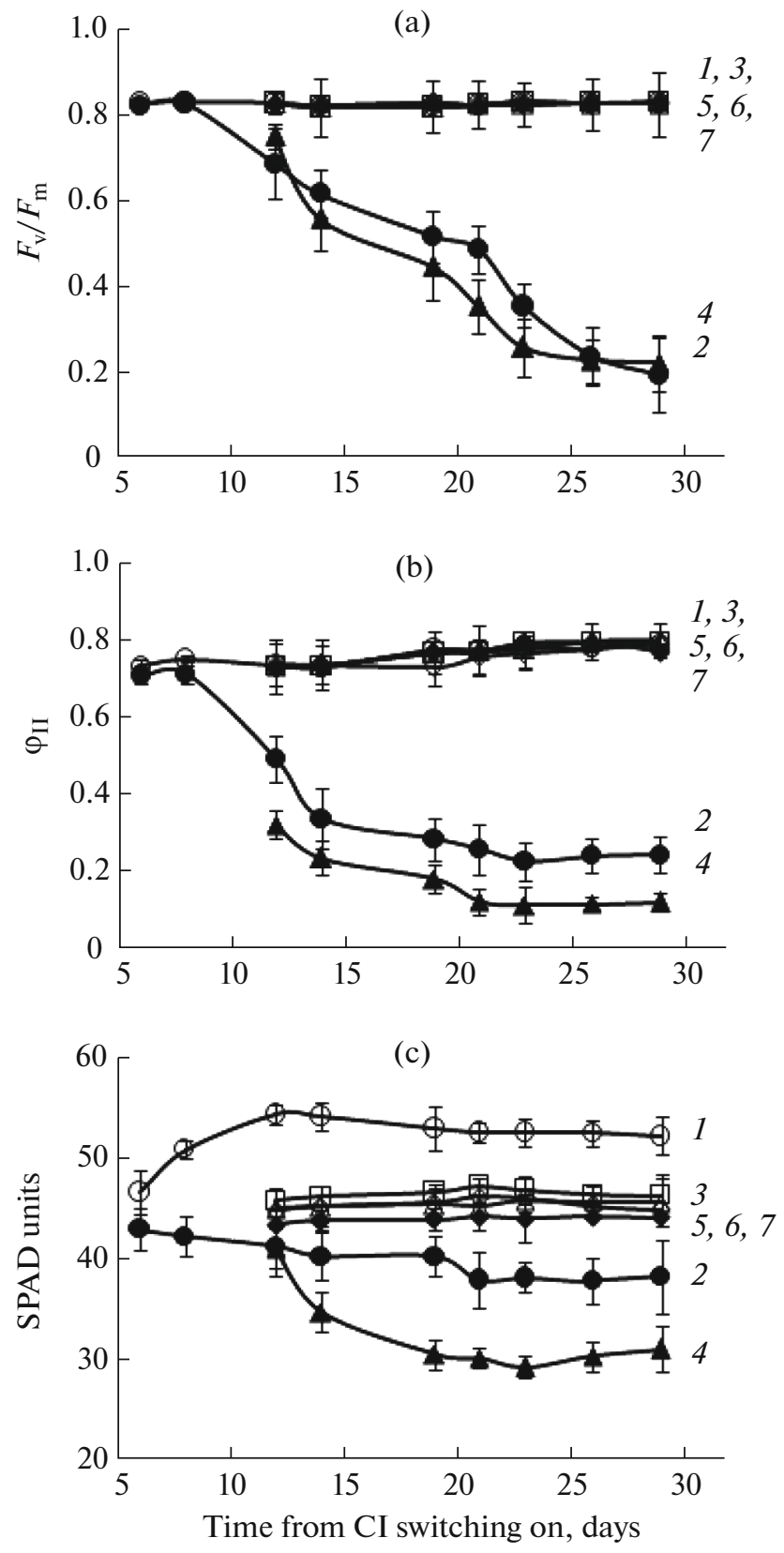

Fig. 5. (a) Maximum $F_{\mathrm{v}} / F_{\mathrm{m}}$ and (b) actual $\varphi_{\mathrm{II}}$ quantum yields of the PSII photochemical activity, and (c) relative content of chlorophyll in the $S$. lycopersicum leaves. (1) The third, (3) fifth, and (6) seventh leaves of the control plants grown under 16-h photoperiod. (2) The 3A-lag2, (4) 5A-lag1, (5) 5C-log2, and (7) 7C- $\log 1$ leaves of CL-treated plants.

mulation of total phenolic compounds are observed in the lettuce plants continuously illuminated for 2 days before a harvest [28].

Anthocyanins are known to fulfill photoprotective function and contribute to maintenance of a balance between light absorption and $\mathrm{CO}_{2}$ fixation. Thus, they restrict the possibility of photooxidative damage [29]. In the present study, we did not assay these com- 
pounds but observed a violet color at lower sides of the CL-treated leaves, which did not show the symptoms of photodamage. It is not excluded that anthocyanins accumulated in these leaves and also enhanced their antioxidant capacity.

In the leaves treated by CL at the log-phase, the brief decrease in $F_{\mathrm{v}} / F_{\mathrm{m}}$ and $\varphi_{\mathrm{II}}$ was observed by us and also other authors on other objects [28]. This evidence indicates that plants sense a surplus irradiation and protect themselves from its harmful action. In these instances, the decrease in $F_{\mathrm{v}} / F_{\mathrm{m}}$ and $\varphi_{\mathrm{II}}$ does not affect the photosynthetic capacity of the leaves but points to the dynamic photoinhibition preventing the photosynthetic apparatus from injury [30]. It is uncertain so far whether this photoinhibition is a response to stress or a protective adaptation coordinating the photosynthetic reactions of the light phase with a complicated and branched reaction chain occurring at the dark phase.

In general, the effect of the leaf position on a plant is difficult to distinguish from the effect of the leaf growth phase. Naturally, the leaves with larger ordinal numbers undergo earlier developmental stages at the oneset of CL. On the plants of equal age, we have compared the leaves of different numbers passing the equal growth phases (although different as to the particular location-at the beginning or in the middle of one phase). As a result, we came to the conclusion that the leaf number is not a definitive factor for the CL sensitivity. In fact, the leaves of the different numbers that were treated by CL from the lag-phase bore clear symptoms of photodamage. In the meantime, the leaves on different positions treated by CL from the logphase were like each other in their much greater tolerance to CL. In the damaged leaves, the occurrence of chlorosis increased with the leaf number, in other words, in the subsequent leaves. Apparently, this took place because the leaves of the larger numbers were affected by CL from the earlier developmental stages.

Therefore, the presented experiments pointed to the leaf growth phase at which it is subjected to CL as the key condition determining its sensitivity to this factor. The age-dependent changes in the leaf sensitivity or tolerance to CL are presumably related to the different activities of the AOS components, including antioxidant enzymes. The leaves that have been treated by $\mathrm{CL}$ at the lag-phase are incapable of withstanding the subsequent oxidative stress because of the inadequate activity of AOS enzymes; photodamage, manifesting as interveinal chlorosis, arises on them as a consequence. By contrast, the leaves that had passed the lag-phase under normal light conditions and have been exposed to CL during the log-phase, turn out to be more CL-tolerant. They possess more active AOS enzymes CAT, APO, and GPO. As a consequence, the oxidative stress caused by the excessive light does not develop. The plant tolerance to CL does not significantly depend on the leaf ordinal number and increases with the plant age.

\section{ACKNOWLEDGMENTS}

This work was carried out on equipment from the Center of Collective Use of the Karelian Research Center (Russian Academy of Sciences) in terms of State Task no. 0218-2019-0074.

\section{FUNDING}

This work was supported by the Russian Foundation for Basic Research, project no. 20-016-00033a.

\section{COMPLIANCE WITH ETHICAL STANDARDS}

Conflict of interests. The authors declare that they have no conflicts of interest.

Statement on the welfare of humans or animals. This article does not contain any studies involving humans or animals performed by any of the authors.

\section{OPEN ACCESS}

This article is licensed under a Creative Commons Attribution 4.0 International License, which permits use, sharing, adaptation, distribution and reproduction in any medium or format, as long as you give appropriate credit to the original author(s) and the source, provide a link to the Creative Commons license, and indicate if changes were made. The images or other third party material in this article are included in the article's Creative Commons license, unless indicated otherwise in a credit line to the material. If material is not included in the article's Creative Commons license and your intended use is not permitted by statutory regulation or exceeds the permitted use, you will need to obtain permission directly from the copyright holder. To view a copy of this license, visit http://creativecommons.org/licenses/by/4.0/.

\section{REFERENCES}

1. Zha, L., Zhang, Y., and Liu, W., Dynamic responses of ascorbate pool and metabolism in lettuce to long-term continuous light provided by red and blue LEDs, Environ. Exp. Bot., 2019, vol. 163, p. 15.

https://doi.org/10.1016/j.envexpbot.2019.04.003

2. Sysoeva, M.I., Markovskaya, E.F., and Shibaeva, T.G., Plant under continuous light: a review, Plant Stress, 2010, vol. 4, p. 5.

3. Velez-Ramirez, A.I., van Ieperen, W., Vreugdenhil, D., and Millenaar, F.F., Plants under continuous light, Trends Plant Sci., 2011, vol. 16, p. 310. https://doi.org/10.1016/j.tplants.2011.02.003

4. Shibaeva, T.G. and Titov, A.F., Influence of continuous illumination on the pigment complex of family Solanacea plants, Tr. Karel. Nauchn. Tsentra, Ross. Akad. Nauk, Ser. Eksp. Biol., 2017, no. 5, p. 111. https://doi.org/10.17076/eb498

5. Kitaya, Y., Niu, G., Kozai, T., and Ohashi, M., Photosynthetic photon flux, photoperiod, and $\mathrm{CO}_{2}$ concentration affect growth and morphology of lettuce plug transplants, Hortic. Sci., 1998, vol. 33, p. 988. https://doi.org/10.21273/HORTSCI.33.6.988

6. Ohyama, K., Manabe, K., Omura, Y., Kubota, C., and Kozai, T., A comparison between closed-type and open-type transplant production systems with respect 
to quality of tomato plug transplants and resource consumption during summer, Environ. Control Biol., 2003, vol. 41 , p. 57.

https://doi.org/10.2525/ecb1963.41.57

7. Hao, X., Zhang, Y., Guo, X., Little, C., Zheng, J., and Khosla, S., Temperature drop improved responses of greenhouse fruit vegetables to long photoperiod of supplemental lighting, Acta Hortic., 2017, vol. 1182, p. 185. https://doi.org/10.17660/ActaHortic.2017.1182.22

8. Lanoue, J., Zheng, J., Little, C., Thibodeau, A., Grodzinski, B., and Hao, X., Alternating red and blue light-emitting diodes allows for injury-free tomato production with continuous lighting, Front. Plant Sci., 2019, vol. 10, p. 1114.

https://doi.org/10.3389/fpls.2019.01114

9. Guo, X., Hao, X., Zheng, J.M., Little, C., and Khosla, S., Response of greenhouse mini-cucumber to different vertical spectra of LED lighting under overhead high pressure sodium and plasma lighting, Acta Hortic., 2016, vol. 1134 , p. 87. https://doi.org/10.17660/ActaHortic.2016.1134.12

10. Hao, X., Zhang, Y., Guo, X., Little, C., and Zheng, J., Dynamic temperature control strategy with a temperature drop improves responses of greenhouse tomatoes and sweet peppers to long photoperiods of supplemental lighting and saves energy, Acta Hortic., 2018, vol. 1227, p. 291.

https://doi.org/10.17660/ActaHortic.2018.1227.35

11. Hao, X., Guo, X., Lanoue, J., Zhang, Y., Cao, R., Zheng, J., Little, C., Leonardos, D., Kholsa, S., Grodzinski, B., and Yelton, M., A review on smart application of supplemental lighting in greenhouse fruiting vegetable production, Acta Hortic., 2018, vol. 1227, p. 499. https://doi.org/10.17660/ActaHortic.2018.1227.63

12. Nelson, J.A. and Bugbee, B., Economic analysis of greenhouse lighting: light emitting diodes vs. high intensity discharge fixtures, PLoS One, 2014, vol. 9, p. e99010. https://doi.org/10.1371/journal.pone.0099010

13. Velez-Ramirez, A., Carreno-Quintero, N., Vreugdenhil, D., Millenaar, F.F., and van Ieperen, W., Sucrose and starch content negatively correlates with PSII maximum quantum efficiency in tomato (Solanum lycopercicum) exposed to abnormal light/dark cycles and continuous light, Plant Cell Physiol., 2017, vol. 58, p. 1339. https://doi.org/10.1093/pcp/pcx068

14. Velez-Ramirez, A.I., Dünner-Planella, G., Vreugdenhil, D., Millenaar, F.F., and van Ieperen, W., On the induction of injury in tomato under continuous light: circadian asynchrony as the main triggering factor, Funct. Plant Biol., 2017, vol. 6, p. 597. https://doi.org/10.1071/FP16285

15. Velez-Ramirez, A., Vreugdenhil, D., Millenaar, F.F., and van Ieperen, W., Phytochrome A protects tomato plants from injuries induced by continuous light, Front. Plant Sci., 2019, vol. 10, p. 19. https://doi.org/10.3389/fpls.2019.00019

16. Velez-Ramirez, A.I., van Ieperen, W., Vreugdenhil, D., van Poppel, P.M.J.A., Heuvelink, E., and Millenaar, F.F., A single locus confers tolerance to continuous light and allows substantial yield increase in tomato, Nat. Commun., 2014, vol. 5, p. 4549.

https://doi.org/10.1038/ncomms5549

17. Lisovskii, G.M. and Dolgushev, V.A., Ocherki chastnoi svetokul'tury rastenii (Particular Plant Photoculture), Novosibirsk: Nauka, 1986.
18. Hillman, W.S., Injury of tomato plants by continuous light and unfavorable photoperiodic cycles, Am. J. Bot., 1956, vol. 43, p. 89. https://doi.org/10.2307/2438816

19. Lichtenthaler, H.K. and Wellburn, A.R., Determinations of total carotenoids and chlorophylls $a$ and $b$ of leaf extracts in different solvents, Biochem. Soc. Trans., 1983, vol. 603, p. 591.

https://doi.org/10.1042/bst0110591

20. Shibaeva, T.G., Mamaev, A.V., and Sherudilo, E.G., Evaluation of a SPAD-502 PLUS chlorophyll meter to estimate chlorophyll content in leaves with interveinal chlorosis, Russ. J. Plant Physiol., 2020, vol. 67, p. 690. https://doi.org/10.1134/S1021443720040160

21. Maxwell, K. and Johnson, G.N., Chlorophyll fluorescence-a practical guide, J. Exp. Bot., 2000, vol. 51, p. 659. https://doi.org/10.1093/jexbot/51.345.659

22. Burritt, D.J. and Mackenzie, S., Antioxidant metabolism during acclimation of Begonia $\times$ erythrophylla to high light levels, Ann. Bot., 2003, vol. 91, p. 783. https://doi.org/10.1093/aob/mcg076

23. Tarakanov, I.G., Photoperiodism in crops, Izv. Timiryazevsk. S-kh. Akad., 2014, vol. 6, p. 38.

24. Khudairi, A.-K. and Hammer, K.C., The relative sensitivity of Xanthium leaves of different ages to photoperiodic induction, Plant Physiol., 1954, vol. 29, p. 251. https://doi.org/10.1104/pp.29.3.251

25. Hague, M.S., Kjaer, K.H., Rosenqvist, E., and Ottosen, C.O., Continuous light increases growth, daily carbon gain, antioxidants, and alters carbohydrate metabolism in a cultivated and a wild tomato species, Front. Plant Sci., 2015, vol. 6, p. 522. https://doi.org/10.3389/fpls.2015.00522

26. Murage, E.N. and Masuda, M., Response of pepper and eggplant to continuous light in relation to leaf chlorosis and activities of antioxidative enzymes, Sci. Hortic. (Amsterdam), 1997, vol. 70, p. 269. https://doi.org/10.1016/S0304-4238(97)00078-2

27. Zhou, W.L., Liu, W.K., and Yang, Q.C., Quality changes in hydroponic lettuce grown under pre-harvest short-duration continuous light of different intensities, J. Hortic. Sci. Biotechnol., 2012, vol. 87, p. 429. https://doi.org/10.1080/14620316.2012.11512890

28. Bian, Z.-H., Cheng, R.-F., Yang, Q.-C., and Wang, J., Continuous light from red, blue, and green light-emitting diodes reduces nitrate content and enhances phytochemical concentrations and antioxidant capacity in lettuce, J. Am. Soc. Hortic. Sci., 2016, vol. 141, p. 186. https://doi.org/10.21273/JASHS.141.2.186

29. Steyn, W.J., Wand, S.J.E., Holcroft, D.M., and Jacobs, G., Anthocyanins in vegetative tissues: a proposed unified function in photoprotection, New Phytol., 2002, vol. 155 , p. 349.

https://doi.org/10.1046/j.1469-8137.2002.00482.x

30. Osmond, B. and Förster, B., Photoinhibition: then and now, in Photoprotection, Photoinhibition, Gene Regulation, and Environment, Adv. Photosynth. Respir., vol. 21, Demmig-Adams, B., Adams, W.W., and Mattoo, A.K., Eds., Dordrecht: Springer-Verlag, 2008. https://doi.org/10.1007/1-4020-3579-9_2

Translated by A. Aver'yanov 